\title{
Cortical remodeling during menopause, rheumatoid arthritis, glucocorticoid and bisphosphonate therapy
}

\author{
Daniel Aeberli*1 and Georg Schett ${ }^{2}$
}

\begin{abstract}
Bone mass, bone geometry and its changes are based on trabecular and cortical bone remodeling. Whereas the effects of estrogen loss, rheumatoid arthritis (RA), glucocorticoid (GC) and bisphosphonate (BP) on trabecular bone remodeling have been well described, the effects of these conditions on the cortical bone geometry are less known. The present review will report current knowledge on the effects of RA, GC and $\mathrm{BP}$ on cortical bone geometry and its clinical relevance. Estrogen deficiency, RA and systemic GC lead to enhanced endosteal bone resorption. While in estrogen deficiency and under GC therapy endosteal resorption is insufficiently compensated by periosteal apposition, RA is associated with some periosteal bone apposition resulting in a maintained load-bearing capacity and stiffness. In contrast, BP treatment leads to filling of endosteal bone cavities at the epiphysis; however, periosteal apposition at the bone shaft seems to be suppressed. In summary, estrogen loss, RA and GC show similar effects on endosteal bone remodeling with an increase in bone resorption, whereas their effect on periosteal bone remodeling may differ. Despite over 50 years of GC therapy and over 25 years of PB therapy, there is still need for better understanding of the skeletal effects of these drugs as well as of inflammatory disease such as RA on cortical bone remodeling.
\end{abstract}

\section{Introduction}

Rheumatoid arthritis (RA) is a chronic inflammatory joint disease characterized by destruction of periarticular bone and cartilage and soft-tissue damage, leading to

*Correspondence: daniel.aeberli@insel.ch

'Department of Rheumatology and Clinical Immunology/Allergology, Inselspital Bern, University of Bern, $\mathrm{CH}-3012$ Bern, Switzerland

Full list of author information is available at the end of the article impaired joint function [1]. Bone erosion, periarticular osteopenia and systemic bone loss, are central features of RA [2]. In a recent cross-sectional study we found that RA patients had thinner cortices at the shafts of the tibia, radius and metacarpal bone, and that the outer diameter of the metacarpal bone was increased. Disease severity, measured by the extent of erosions and the cumulative dose of glucocorticoids (GCs), correlated negatively with shaft cortical thickness [3]. However, despite increased outer circumference and thinner cortical shaft, the calculated load-bearing capacity (strength strain index) of long bone shafts was not impaired in RA patients and adaptation to muscular strength remained unchanged [4].

In the last years, several case studies have linked RA with increased risk of bone shaft fractures at the metatarsal, tibial and femoral bones [5-7]. Since these fractures occur without previous trauma, and are not at typical locations for osteoporosis-associated fractures, they are called insufficiency or atypical fractures. The reasons for these fractures are not yet known, but associated factors are estrogen deficiency, RA, diabetes, GC therapy and treatment with anti-resorptive drugs, such as bisphosphonates (BPs). In a recent report of summarized clinical data on cases with shaft fractures associated with BP, the task force of the American Society for Bone Mineral Research [6] found that patients with atypical fractures of the femur had a higher number of comorbid conditions such as RA (odds ratio $=16.5$ ) and underwent therapy with GC (odds ratio $=5.2$ ) [8].

Findings of a potential association of BP with insufficiency fractures are in strong contrast to the actual therapy concept and impede the clinician's decision-making in treating RA patients on GCs with BP therapy. Hence, there is a need to elucidate the effect of RA, BP and GC (and their combination) on long-term adaptation of bone geometry and bone mineral density.

\section{Physiology of adaptation of bone geometry}

Bone adapts its shape in response to prevailing loads by bone modeling and remodeling at the outer and inner envelopes of the cortical shaft. During bone modeling 
(construction, growth) bone is deposited at the periosteal surface without prior resorption on the endosteal surface, leading to an increase in cortical diameter (Figure 1a) [9]. During bone remodeling (reconstruction, lifetime adaptation to load and age), osteoclasts resorb a small volume of bone at a distinct location at the inner site of the cortex adjacent to the marrow (Figure 1b) [10]. If periosteal apposition increases (as an adaptive response) to compensate for the loss of strength (caused by endosteal bone loss), there will be no loss in bone strength (Figure 1c) [11-13]. Alternatively, if periosteal apposition is impaired, endosteal resorption will produce cortical thinning and loss of bone mass and strength, predisposing to fractures.

Various factors influence adaptation of bone geometry. These factors include the menopause, GC therapy and treatment with anti-resorptive drugs, as well as diseases such as RA, hyperparathyroidism, diabetes mellitus, hypophosphatasia and vitamin D deficiency and mechanical factors such as weight. In the following paragraphs, current knowledge on the main factors causing bone loss and potentially leading to fractures in patients with RA will be summarized and resulting research questions highlighted.

\section{Menopause}

Estrogen loss during the menopause is the most common cause of fractures in older people. Trabecular bone loss occurs years before the menopause; at the onset of estrogen decline, a phase of rapid bone loss starts, leading to loss of an approximate mean of $10 \%$ of bone at the spine and about $5 \%$ at the hip over a period of 5 years $[14,15]$. This phase is characterized by bone resorption, leading to trabecular thinning and perforation, resulting in a loss of connectivity [16]. This initial acute phase the high-turnover phase - is followed by a long-lasting period of slower bone loss where the dominant microarchitecture change is trabecular thinning and increased cortical porosity [17].

On a cellular level, the high-turnover phase is caused by an increased activity of osteoclasts, driven by the increased production of receptor activator of NF- $\mathrm{kB}$ ligand [18-20]. The second phase is caused by impaired osteoblastic activity due to increased osteoblast death and decreased function [21]. Estrogen therapy blunts bone resorption and stimulates bone formation. The dominant effect of estrogen is the inhibition of osteoclast differentiation and activation, and, to a lesser extent, impairment of apoptosis of the osteoblasts [19,20,22]. Studies on bone geometry and strength of the one-third distal radius in perimenopausal and postmenopausal women showed an accelerated endosteal resorption and decreased periosteal apposition at the radius shaft. This endosteal resorption during the postmenopausal years leads to cortical thinning - and because the outward apposition of bone is minimal, the cortical crosssectional area and bending strength decrease (Figure 2a) [23].

Thinning of the cortical shaft thickness of the radius and tibia is associated with an increased fracture risk [24]. In estrogen-treated women, loss of bone strength was partially prevented [24] and the risk of vertebral and hip fracture incidence in postmenopausal women declined [25]. In summary, estrogen deficiency leads to thinning and loss of bony trabeculae as well as increased endosteal resorption and impaired periosteal bone apposition, resulting in a net loss of bone with diminished strength to compression and bending.

\section{Rheumatoid arthritis}

RA is a chronic inflammatory joint disease characterized by destruction of periarticular bone and cartilage and soft-tissue damage, leading to impaired joint function [1]. The general consensus is that the pathogenic process of bone loss in RA patients is due to the abundance of osteoclasts [26]. Bone erosion, periarticular osteopenia and systemic bone loss are central features of RA [2]. Chronic inflammatory diseases such as RA cause skeletal breakdown and enhance the risk of nontraumatic fractures [27,28]. Approximately $25 \%$ of patients with early RA show an osteopenic bone mineral density at the spine or hip before the onset of therapy, and $10 \%$ have osteoporosis [29-32]. A large case-control study based on the British General Practice Research Database has shown that RA doubles the risk of hip and vertebral fractures, supporting the concept that the effect of RA is independent and additive to GC [33].

With a newly established protocol using peripheral quantitative computed tomography (QCT) we investigated the differences in volumetric bone mineral density (BMD) and bone geometry at the metacarpal bone, tibia and radius in 50 female RA patients and compared it with 100 healthy female controls [3]. We found that RA patients had significantly lower trabecular volumetric BMD at the distal epiphyses of the radius $(-19 \%)$, tibia $(-14 \%)$ and metacarpal bone $(-12 \%)$. At the shafts of these bones RA patients had thinner cortices $(-7 \%$ to $-16 \%$ ), and at the metacarpal shaft the outer diameter was increased by $5 \%$ (Figure $2 \mathrm{~b}$ ). The extent of bone erosions and the cumulative dose of GCs correlated negatively with trabecular and total volumetric BMD as well as with shaft cortical thickness [3]. In a subsequent study with 64 RA patients and 128 healthy controls, we assessed factors associated with differences in bone geometry between RA patients and healthy controls. Based on linear models with explanatory variables (muscle cross-sectional area, age, RA status and sex), we found that patients with RA showed a greater age-related decrease in cortical thickness with a concomitant increase 


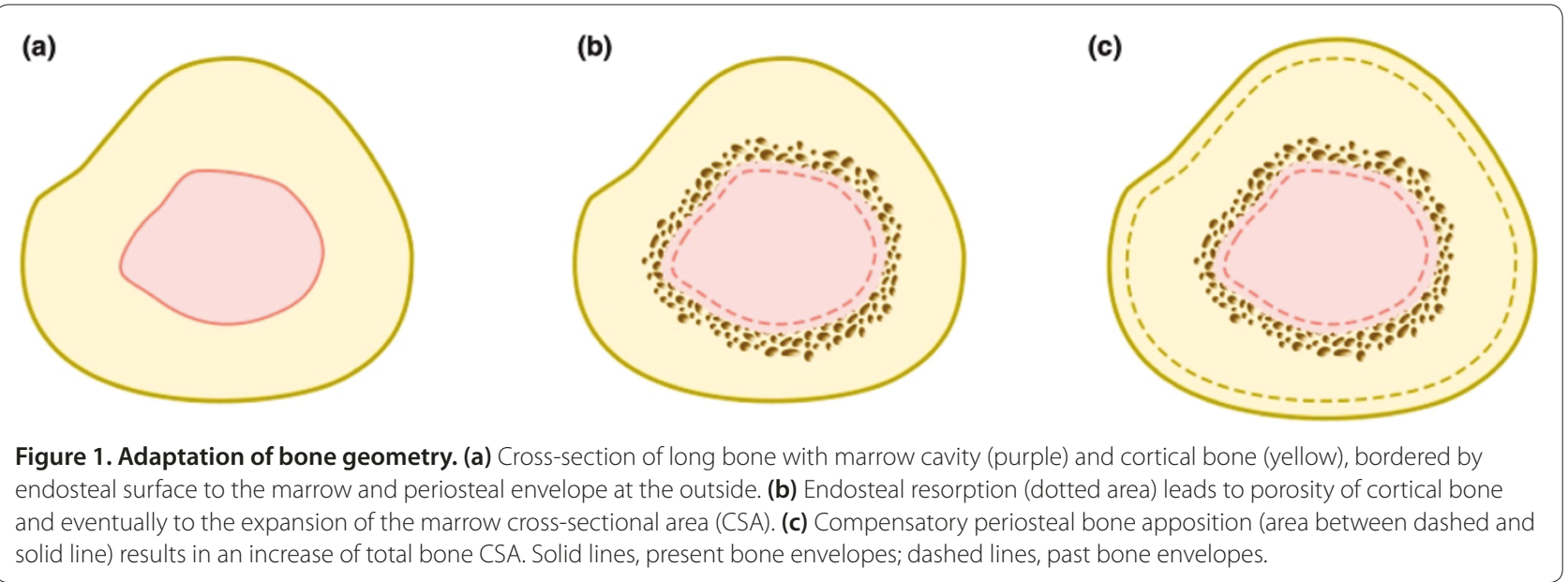

in outer bone circumference consistent with an enhanced aging pattern [4].

These observations suggest that the biological changes of endosteal resorption and periosteal bone apposition found in healthy populations $[11,23,34]$ are accelerated in patients with RA. Possible explanations for this process may be inflammation-driven endosteal resorption, which was also found in human juvenile idiopathic arthritis [35], experimentally induced inflammatory knee arthritis or adjuvant-induced arthritis [36-38]. Similarly, inhibition of bone resorption by the anti-receptor activator of NF- $\mathrm{kB}$ ligand antibody denosumab prevented metacarpal shaft bone loss in patients with RA [39]. Periosteal bone formation has been found in human studies [35] and in animal studies [36-38], with one of these studies observing that periosteal bone formation occurred after the endosteal resorption, when inflammation had already subsided [38]. This observation suggests that periosteal bone formation may be a compensatory mechanism to restore bone strength. In other words, the calculated load-bearing capacity of RA patients was not impaired and adaptation to muscular strength remained unchanged [4].

In summary, RA is associated with an increased endosteal bone resorption and compensatory periosteal bone formation of the affected shafts leading to a change in geometry with maintained strength. Longitudinal data for the effects of inflammation on bone geometry and volumetric BMD in patients with RA have not yet been published.

\section{Glucocorticoids}

GC use, quantified either by daily or cumulative dosage, is strongly related to an increased fracture risk $[40,41]$. Prednisone equivalent $>5 \mathrm{mg}$ daily is associated with vertebral fractures in postmenopausal women within the first 6 months of treatment [42]. The relative risk for fractures in GC users in a general practice research database is 2.86 ( $95 \%$ confidence interval $=2.31$ to 3.16 ) for the spine and 2.01 (95\% confidence interval $=1.47$ to 2.29) for the hip compared with subjects not using GCs [42]. The areal BMD at the lumbar spine and hip showed an up to $12 \%$ increased bone loss in GC users compared with in nonusers of similar age and sex [42]. A metaanalysis of the relationship between areal BMD changes and fractures showed that low areal BMD was associated with a relative risk of 1.48 for vertebral fractures and 1.41 for hip fractures [43]. Further, it has been shown that fractures occurred at a younger age in male GC users compared with nonusers at comparable areal BMD [44]. This finding indicates that GCs not only lead to decreased areal BMD, but fractures occur at an even higher rate than that expected based on areal BMD. One can therefore speculate that there is not only a loss in bone mass but also in bone quality in GC users. The effects of GC on bone cells include early and quick induction of osteoclastogenesis leading to increased bone resorption as well as apoptosis of osteoblasts and osteocyts [45].

Histomorphometric analyses showed trabecular thinning and reduced osteoid thickness, a marker for osteoblastic activity in GC users [46,47]. At the iliac crest, cortical porosity and Haversian canal density were higher in patients treated with GCs [48]. Using QCT of the spine, rapid decline of vertebral trabecular volumetric BMD was found upon GC treatment with subsequent recovery following discontinuation [49]. Thinning of the cortical shell at the distal radius was found by peripheral QCT [50,51] and at the proximal femur by QCT [52]. Consistent with these results, GC administration to ovariectomized sheep showed that the cortical width and cortical bone area were reduced by 7 to $8 \%$ and the marrow area increased by $8 \%$ in GC-treated animals compared with controls (Figure 2a) [53]. Trabecular bone formation in the GC-treated animals decreased by $68 \%$ 

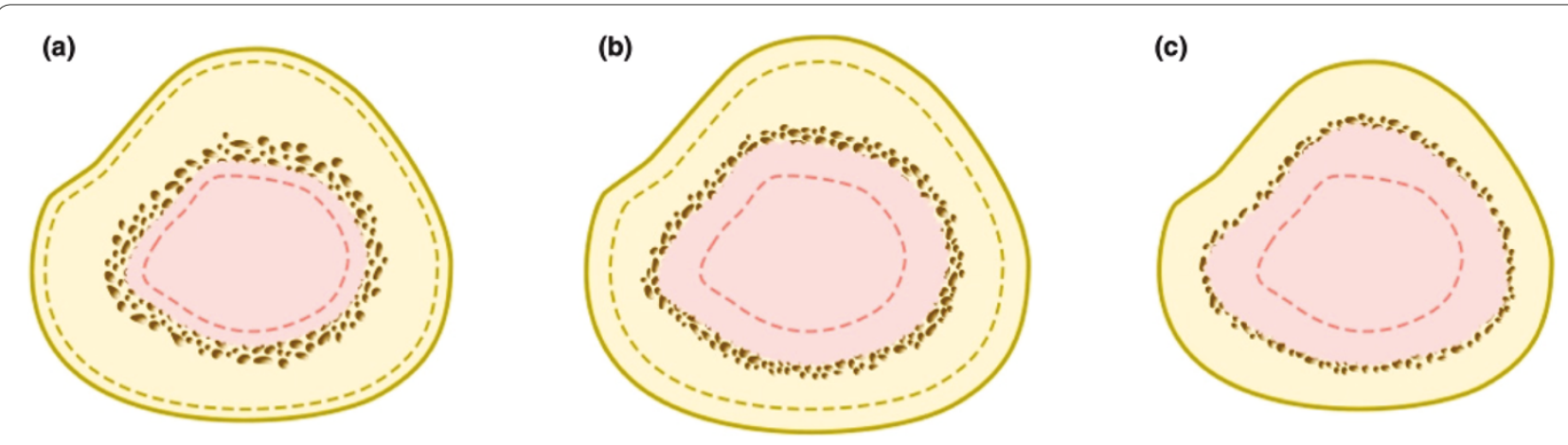

Figure 2. Bone shaft geometry adaptation to effects of estrogen deficiency, glucocorticoid therapy, rheumatoid arthritis and

bisphosphonate. (a) Estrogen deficiency or usage of systemic glucocorticoids leads to enhanced osteoclastogenesis and thus endosteal resorption and cortical porosity. However, bone formation in these conditions is inhibited, resulting in a decreased periosteal bone apposition that insufficiently compensates for the endosteal resorption. Solid lines, present bone envelopes; dashed lines, past bone envelopes. (b) Under inflammatory conditions such as rheumatoid arthritis (RA) endosteal bone resorption is accelerated, leading to an increase of marrow crosssectional area (CSA). Periosteal bone apposition seems to compensate the endosteal bone loss and leads to an increase in total and cortical shaft CSA, resulting in a maintained estimated compression and bending strength. (c) Preliminary data in RA patients indicate that bisphosphonate may inhibit periosteal bone apposition and does not always stop endosteal bone resorption. In these cases, the endosteal resorption cannot be compensated and the cortical thinning predisposes to fractures of long bone shaft.

after 2 months and by $90 \%$ after 4 months. The apparent trabecular BMD and compressive stiffness were reduced by $34 \%$ and $55 \%$, respectively. The results are consistent with a substantially reduced bone formation in the cortical and trabecular bone and reduced cortical width due to increased endosteal resorption. Impaired cortical bone remodeling together with increased cortical porosity bears the potential for increased fracture risk at appendicular bone sites such as the femur and tibia $[48,53]$.

In summary, BMD and bone quality are reduced upon GC treatment due to increased endosteal resorption, cortical porosity and impaired periosteal apposition. Longitudinal data on bone shaft geometry changes in GC-treated patients, however, are as yet absent.

\section{Bisphosphonates}

BP therapy is the strategy of choice for prevention and treatment of bone loss and fractures associated with osteoporosis. Current clinical practice treats patients on high-dose long-term GC therapy with $\mathrm{BP}$ to prevent bone loss. BP therapy has been shown to reduce the relative risk for new vertebral and hip fractures in postmenopausal women by $70 \%$ and $50 \%$, respectively, over 3 years [54]. Indications for treatment with BPs are a quantitative estimate of the 10-year probability of a major osteoporotic fracture (clinical spine, hip, forearm or shoulder) exceeding 15 to 30\% [55-57], inadequate vertebral fracture or GC therapy depending on the risk category [58].

BPs accumulate in the bone's hydroxyapatite mineral phase, particularly at sites of active resorption $[59,60]-$ where the nitrogen-containing BPs enter osteoclasts and reduce resorption by initiating early osteoclast death
[61]. Recent retrospective studies and case reports suggest that long-term BP therapy may result in the suppression of bone turnover and confer a predisposition to increased bone fragility, with an increased risk of atypical fractures [62]. The number of atypical fractures is low - corresponding to an incidence of subtrochanteric fractures of 3 per 10,000 person-years - compared with the overall incidence of hip fractures (103 per 10,000 person-years) [63]. Nevertheless, long-term BP use is more likely and the duration of BP use longer in patients with subtrochanteric and femoral shaft fractures compared with patients with typical osteoporotic hip fracture $[63,64]$. Hip fracture incidence declined by $12.8 \%$ from 1996 to 2007, since BPs were approved, whereas the number of subtrochanteric and femoral shaft fractures remained stable or even increased in the same period [65]. This coincidence made the US Food and Drug Administration issue an alert with a warning about the 'possible risk of rare atypical femur fractures associated with BP treatment in osteoporosis patients' [66].

A causal relationship between BP use and atypical femur fractures has not been established, but preclinical data evaluating the effects of BPs lend biologic plausibility to a potential association with long-term $\mathrm{BP}$ use. Of special interest was the finding that patients with femoral shaft fractures had a higher number of comorbid conditions - for example, diabetes mellitus, RA (odds ratio $=16.5)$ and concomitant use of additional antiresorptive agent (such as estrogen, raloxifene or calcitonin) or systemic GCs (odds ratio $=5.2$ ) - than those with typical hip fractures [8]. This association is striking since guidelines suggest treating patients with RA undergoing GC treatment with BPs, either preventative 
to alleviate GC-induced osteoporosis or as therapy of already established osteoporosis [58]. In a recent longitudinal study using high-resolution computed tomography to measure the effect of alendronate treatment in postmenopausal women with low BMD, changes in trabecular and endosteal compartments at the epiphyses of tibia and radius were found [67]. Particularly at the weight-bearing tibia, a filling of endosteal bone cavities was found with a concomitant decrease in the medullary area [67]. At the tibia shaft, however, increased medullary area with unaltered periosteal circumference was seen in postmenopausal RA patients treated with alendronate [68] (Figure 2c).

In summary, the positive effects of BP therapy in reducing fracture risk are undoubted; in patients with comorbid conditions such as RA and GC use, however, BPs seem to be associated with atypical femoral fractures, for which the reason is not yet known. The recent reports of the potential association of BPs with atypical femur shaft fractures and the recommendations to treat RA patients on GCs with BP therapy are in stark contrast to the prevailing advice and therefore impede the clinician's decision-making in treating a large proportion of RA patients. Further research is needed to address these questions.

\section{Conclusion}

Current knowledge about the adaptation of bone shaft geometry to effects of estrogen deficiency, RA and systemic GC therapy suggests an enhanced endosteal bone resorption. While in estrogen deficiency and under GC therapy this endosteal resorption is insufficiently compensated by periosteal apposition (Figure 2a), in the RA it seems to be compensated by increased periosteal bone apposition (Figure 2b) resulting in a maintained load-bearing capacity and stiffness. BP therapy results in filling of endosteal bone cavities and hence reduction of the endosteal diameter at the epiphysis. However, periosteal apposition upon BP treatment in patients with osteoporosis has not yet been seen (Figure 2c). More so, studies elucidating the effect of $\mathrm{BP}$ treatment on the bone geometry of patients with RA are missing. Further, the effects of concomitant use of GCs and BPs on the bone shaft's inner and outer bone envelope are unexplored. There is a need for answering these questions, and studies that further clarify the effect of GCs and BPs (and their combination) on bone geometry and fragility will shed some light on these points.

\section{Rheumatology key messages}

- Estrogen loss, RA and GC show increased endosteal resorption of bone shaft.

- Periosteal bone remodeling of the bone shaft may be increased under inflammatory conditions.
- Studies are needed to elucidate the effect of BP on periosteal apposition under inflammatory conditions.

\section{Abbreviations}

BMD, bone mineral density; BP, bisphosphonate; GC, glucocorticoid; NF, nuclear factor; QCT, quantitative computed tomography; RA, rheumatoid arthritis.

\section{Acknowledgements}

The authors would like to thank Prisca Eser for editing the manuscript.

\section{Competing interests}

The authors declare that they have no competing interests.

\section{Author details}

'Department of Rheumatology and Clinical Immunology/Allergology, Inselspital Bern, University of Bern, CH-3012 Bern, Switzerland. ${ }^{2}$ Department of Internal Medicine 3, University Clinic of Erlangen-Nuremberg, Ulmenweg 18, 91054 Erlangen, Germany.

Published: 21 March 2013

\section{References}

1. Stach CM, Bäuerle M, Englbrecht M, Kronke G, Engelke K, Manger B, Schett G: Periarticular bone structure in rheumatoid arthritis patients and healthy individuals assessed by high-resolution computed tomography. Arthritis Rheum 2010, 62:330-339.

2. Kamen DL, Alele JD: Skeletal manifestations of systemic autoimmune diseases. Curr Opin Endocrinol Diabetes Obes 2010, 17:540-545.

3. Aeberli D, Eser P, Bonel H, Widmer J, Caliezi G, Varisco PA, Möller B, Villiger PM: Reduced trabecular bone mineral density and cortical thickness accompanied by increased outer bone circumference in metacarpal bone of rheumatoid arthritis patients: a cross-sectional study. Arthritis Res Ther 2010, 12:R119.

4. Eser P, Aeberli D, Widmer J, Möller B, Villiger PM: Abnormal bone geometry at the metacarpal bone shaft of rheumatoid arthritis patients with maintained muscle-bone relationship. Arthritis Care Res (Hoboken) 2011, 63:383-389.

5. Kay $\sqcup$, Holland TM, Platt PN: Stress fractures in rheumatoid arthritis: a case series and case-control study. Ann Rheum Dis 2004, 63:1690-1692.

6. Shane E, Burr D, Ebeling PR, Abrahamsen B, Adler RA, Brown TD, Cheung AM, Cosman F, Curtis JR, Dell R, Dempster D,Einhorn TA, Genant HK, Geusens P, Klaushofer K, Koval K, Lane JM, McKiernan F, McKinney R, Ng A, Nieves J, O'Keefe R, Papapoulos S, Sen HT, van der Meulen MC, Weinstein RS, Whyte M; American Society for Bone and Mineral Research: Atypical subtrochanteric and diaphyseal femoral fractures: report of a task force of the American Society for Bone and Mineral Research. J Bone Miner Res 2010, 25:2267-2294.

7. Mäenpää HM, Soini I, Lehto MU, Belt EA: Insufficiency fractures in patients with chronic inflammatory joint diseases. Clin Exp Rheumatol 2002, 20:77-79.

8. Girgis CM, Sher D, Seibel MJ: Atypical femoral fractures and bisphosphonate use. N Engl J Med 2010, 362:1848-1849.

9. Seeman $\mathrm{E}$ : The growth and age-related origins of bone fragility in men. Calcif Tissue Int 2004, 75:100-109.

10. Parfitt AM: The two faces of growth: benefits and risks to bone integrity. Osteoporos Int 1994, 4:382-398.

11. Ruff CB, Hayes WC: Subperiosteal expansion and cortical remodeling of the human femur and tibia with aging. Science 1982, 217:945-948.

12. Ruff $C B$, Hayes WC: Sex differences in age-related remodeling of the femur and tibia. J Orthop Res 1988, 6:886-896.

13. Ahlborg HG, Johnell O, Turner CH, Rannevik G, Karlsson MK: Bone loss and bone size after menopause. N Engl J Med 2003, 349:327-334.

14. Riggs BL, Wahner HW, Melton $\sqcup$ 3rd, Richelson LS, Judd HL, Offord KP: Rates of bone loss in the appendicular and axial skeletons of women. Evidence of substantial vertebral bone loss before menopause. J Clin Invest 1986, 77:1487-1491

15. Riggs BL, Melton LJ, Robb RA, Camp JJ, Atkinson EJ, McDaniel L, Amin S, Rouleau PA, Khosla S: A population-based assessment of rates of bone loss at multiple skeletal sites: evidence for substantial trabecular bone loss in young adult women and men. J Bone Miner Res 2008, 23:205-214. 
16. Eriksen EF, Hodgson SF, Eastell R, Cedel SL, O'Fallon WM, Riggs BL: Cancellous bone remodeling in type I (postmenopausal) osteoporosis: quantitative assessment of rates of formation, resorption, and bone loss at tissue and cellular levels. J Bone Miner Res 1990, 5:311-319.

17. Seeman E, Delmas PD: Bone quality - the material and structural basis of bone strength and fragility. N Eng/ J Med 2006, 354:2250-2261.

18. Khosla S: Update on estrogens and the skeleton. J Clin Endocrinol Metab 2010, 95:3569-3577.

19. Manolagas SC: Birth and death of bone cells: basic regulatory mechanisms and implications for the pathogenesis and treatment of osteoporosis. Endocr Rev 2000, 21:115-137.

20. Manolagas SC, Kousteni S, Jilka RL: Sex steroids and bone. Recent Prog Horm Res 2002, 57:385-409

21. Clowes JA, Riggs BL, Khosla S: The role of the immune system in the pathophysiology of osteoporosis. Immunol Rev 2005, 208:207-227.

22. Vedi S, Purdie DW, Ballard P, Bord S, Cooper AC, Compston JE: Bone remodeling and structure in postmenopausal women treated with longterm, high-dose estrogen therapy. Osteoporos Int 1999, 10:52-58.

23. Szulc P, Seeman E, Duboeuf F, Sornay-Rendu E, Delmas PD: Bone fragility: failure of periosteal apposition to compensate for increased endocortical resorption in postmenopausal women. J Bone Miner Res 2006 , 21:1856-1863

24. Stein EM, Liu XS, Nickolas TL, Cohen A, Thomas V, McMahon DJ, Zhang C, Yin PT, Cosman F, Nieves J, Guo XE, Shane E: Abnormal microarchitecture and reduced stiffness at the radius and tibia in postmenopausal women with fractures. J Bone Miner Res 2010, 25:2572-2581.

25. Cauley JA, Robbins J, Chen Z, Cummings SR, Jackson RD, LaCroix AZ, LeBoff M, Lewis CE, McGowan J, Neuner J,Pettinger M, Stefanick ML, WactawskiWende J, Watts NB; Women's Health Initiative Investigators: Effects of estrogen plus progestin on risk of fracture and bone mineral density: the Women's Health Initiative randomized trial. JAMA 2003, 290:1729-1738.

26. Gravallese EM, Harada Y, Wang JT, Gorn AH, Thornhill TS, Goldring SR: Identification of cell types responsible for bone resorption in rheumatoid arthritis and juvenile rheumatoid arthritis. Am J Pathol 1998, 152:943-951.

27. Spector TD, Hall GM, McCloskey EV, Kanis JA: Risk of vertebral fracture in women with rheumatoid arthritis. BMJ 1993, 306:558.

28. Bernstein CN, Blanchard JF, Leslie W, Wajda A, Yu BN: The incidence of fracture among patients with inflammatory bowel disease. A populationbased cohort study. Ann Intern Med 2000, 133:795-799.

29. Güler-Yüksel M, Bijsterbosch J, Goekoop-Ruiterman YP, de Vries-Bouwstra JK Ronday HK, Peeters AJ, de Jonge-Bok JM,Breedveld FC, Dijkmans BA, Allaart CF, Lems WF: Bone mineral density in patients with recently diagnosed, active rheumatoid arthritis. Ann Rheum Dis 2007, 66:1508-1512.

30. Kanis JA, Burlet N, Cooper C, Delmas PD, Reginster JY, Borgstrom F, Rizzoli R; European Society for Clinical and Economic Aspects of Osteoporosis and Osteoarthritis (ESCEO): European guidance for the diagnosis and management of osteoporosis in postmenopausal women. Osteoporos Int 2008, 19:399-428.

31. Kanis JA, Johnell O, Oden A, Johansson H, McCloskey E: FRAX and the assessment of fracture probability in men and women from the UK. Osteoporos Int 2008, 19:385-397.

32. Kanis JA, McCloskey EV, Johansson H, Strom O, Borgstrom F, Oden A; National Osteoporosis Guideline Group: Case finding for the management of osteoporosis with FRAX - assessment and intervention thresholds for the UK. Osteoporos Int 2008, 19:1395-1408

33. van Staa TP, Geusens P, Bijlsma JW, Leufkens HG, Cooper C: Clinical assessment of the long-term risk of fracture in patients with rheumatoid arthritis. Arthritis Rheum 2006, 54:3104-3112.

34. Russo CR, Lauretani F, Seeman E, Bartali B, Bandinelli S, Di lorio A, Guralnik J, Ferrucci L: Structural adaptations to bone loss in aging men and women. Bone 2006, 38:112-118

35. Roth J, Linge M, Tzaribachev N, Schweizer R, Kuemmerle-Deschner J: Musculoskeletal abnormalities in juvenile idiopathic arthritis - a 4-year longitudinal study. Rheumatology (Oxford) 2007 46:1180-1184

36. Bogoch E, Gschwend N, Bogoch B, Rahn B, Perren S: Juxtaarticular bone loss in experimental inflammatory arthritis. J Orthop Res 1988, 6:648-656.

37. Bogoch E, Gschwend N, Bogoch B, Rahn B, Perren S: Changes in the metaphysis and diaphysis of the femur proximal to the knee in rabbits with experimentally induced inflammatory arthritis. Arthritis Rheum 1989 32:617-624

38. Yu Y, Xiong Z, LV Y, Qian Y, Jiang $S$, Tian Y: In vivo evaluation of early disease progression by X-ray phase-contrast imaging in the adjuvant-induced arthritic rat. Skeletal Radiol 2006, 35:156-164.

39. Sharp JT, Tsuji W, Ory P, Harper-Barek C, Wang H, Newmark R: Denosumab prevents metacarpal shaft cortical bone loss in patients with erosive rheumatoid arthritis. Arthritis Care Res (Hoboken) 2010, 62:537-544.

40. Van Staa TP, Leufkens HG, Abenhaim L, Zhang B, Cooper C: Use of oral corticosteroids and risk of fractures. J Bone Miner Res 2000, 15:993-1000.

41. van Staa TP, Leufkens HG, Abenhaim L, Zhang B, Cooper C: Oral corticosteroids and fracture risk: relationship to daily and cumulative doses. Rheumatology (Oxford) 2000, 39:1383-1389.

42. van Staa TP, Leufkens HG, Cooper C: The epidemiology of corticosteroidinduced osteoporosis: a meta-analysis. Osteoporos Int 2002, 13:777-787.

43. Marshall $\mathrm{D}$, Johnell $\mathrm{O}$, Wedel H: Meta-analysis of how well measures of bone mineral density predict occurrence of osteoporotic fractures. BMJ 1996, 312:1254-1259.

44. Hayashi K, Yamamoto M, Murakawa Y, Yamauchi M, Kaji H, Yamaguchi T, Sugimoto T: Bone fragility in male glucocorticoid-induced osteoporosis is not defined by bone mineral density. Osteoporos Int 2009, 20:1889-1894.

45. Compston J: Management of glucocorticoid-induced osteoporosis. Nat Rev Rheumatol 2010, 6:82-88.

46. Aaron JE, Francis RM, Peacock M, Makins NB: Contrasting microanatomy of idiopathic and corticosteroid-induced osteoporosis. Clin Orthop Relat Res 1989, 243:294-305.

47. Chappard D, Legrand E, Basle MF, Fromont P, Racineux JL, Rebel A, Audran M: Altered trabecular architecture induced by corticosteroids: a bone histomorphometric study. J Bone Miner Res 1996, 11:676-685.

48. Vedi S, Elkin SL, Compston JE: A histomorphometric study of cortical bone of the iliac crest in patients treated with glucocorticoids. Calcif Tissue Int 2005, 77:79-83

49. Laan RF, van Riel PL, van de Putte LB, van Erning $L$, van't Hof MA, Lemmens $J A$ : Low-dose prednisone induces rapid reversible axial bone loss in patients with rheumatoid arthritis. A randomized, controlled study. Ann Intern Med 1993, 119:963-968.

50. Tsugeno H, Tsugeno H, Fujita T, Goto B, Sugishita T, Hosaki Y, Ashida K, Mitsunobu F, Tanizaki Y, Shiratori Y: Vertebral fracture and cortical bone changes in corticosteroid-induced osteoporosis. Osteoporos Int 2002, 13:650-656.

51. Tsugeno H, Nakai M, Okamoto M, Harada S, Mifune T, Mitsunobu F, Ashida K, Hosaki Y, Tanizaki Y, Tsuji T: Bone mineral density in steroid-dependent asthma assessed by peripheral quantitative computed tomography. Eur Respir J 1999, 14:923-927.

52. Lian KC, Lang TF, Keyak JH, Modin GW, Rehman Q, Do L, Lane NE: Differences in hip quantitative computed tomography (QCT) measurements of bone mineral density and bone strength between glucocorticoid-treated and glucocorticoid-naive postmenopausal women. Osteoporos Int 2005, 16:642-650.

53. Schorlemmer S, Ignatius A, Claes L, Augat P: Inhibition of cortical and cancellous bone formation in glucocorticoid-treated OVX sheep. Bone 2005, 37:491-496.

54. Black DM, Delmas PD, Eastell R, Reid IR, Boonen S, Cauley JA, Cosman F, Lakatos P, Leung PC, Man Z, Mautalen C,Mesenbrink P, Hu H, Caminis J, Tong K, Rosario-Jansen T, Krasnow J, Hue TF, Sellmeyer D, Eriksen EF, Cummings SR;HORIZON Pivotal Fracture Trial: Once-yearly zoledronic acid for treatment of postmenopausal osteoporosis. N Engl J Med 2007, 356:1809-1822.

55. Papaioannou A, Morin S, Cheung AM, Atkinson S, Brown JP, Feldman S, Hanley DA, Hodsman A, Jamal SA, Kaiser SM,Kvern B, Siminoski K, Leslie WD; Scientific Advisory Council of Osteoporosis Canada: 2010 clinical practice guidelines for the diagnosis and management of osteoporosis in Canada: summary. CMAJ 2010, 182:1864-1873.

56. Lippuner K: Osteoporosis - whom to treat? The importance of FRAX(R) in Switzerland. Ther Umsch 2012, 69:207-213.

57. Dawson-Hughes B, Looker AC, Tosteson AN, Johansson H, Kanis JA, Melton L 3rd: The potential impact of new National Osteoporosis Foundation guidance on treatment patterns. Osteoporos Int 2010, 21:41-52.

58. Hansen KE, Wilson HA, Zapalowski C, Fink HA, Minisola S, Adler RA Uncertainties in the prevention and treatment of glucocorticoid-induced osteoporosis. J Bone Miner Res 2011, 26:1989-1996.

59. Russell RG, Watts NB, Ebetino FH, Rogers MJ: Mechanisms of action of bisphosphonates: similarities and differences and their potential influence on clinical efficacy. Osteoporos Int 2008, 19:733-759.

60. Masarachia P, Weinreb M, Balena R, Rodan GA: Comparison of the 
distribution of $3 \mathrm{H}$-alendronate and $3 \mathrm{H}$-etidronate in rat and mouse bones. Bone 1996, 19:281-290.

61. Luckman SP, Hughes DE, Coxon FP, Graham R, Russell G, Rogers MJ: Nitrogencontaining bisphosphonates inhibit the mevalonate pathway and prevent post-translational prenylation of GTP-binding proteins, including Ras. J Bone Miner Res 1998, 13:581-589.

62. Watts NB, Diab DL: Long-term use of bisphosphonates in osteoporosis. J Clin Endocrinol Metab 2010, 95:1555-1565.

63. Kelly MP, Wustrack R, Bauer DC, Palermo L, Burch S, Peters K, Cauley J, Ensrud K, Black D: Incidence of subtrochanteric and diaphyseal fractures in older white women: data from the Study of Osteoporotic Fractures. J Bone Miner Res 2010, 25(Suppl 1):poster presentation FR0355.

64. Lenart BA, Neviaser AS, Lyman S, Chang CC, Edobor-Osula F, Steele B, van der Meulen MC, Lorich DG, Lane JM: Association of low-energy femoral fractures with prolonged bisphosphonate use: a case control study. Osteoporos Int 2009, 20:1353-1362.

65. Wang Z, Bhattacharyya T: Trends in incidence of subtrochanteric fragility fractures and bisphosphonate use among the US elderly, 1996-2007. J Bone Miner Res 2011, 26:553-560.

66. US Food and Drug Administration [http://www.fda.gov/NewsEvents/ Newsroom/PressAnnouncements/2010/ucm229171.htm]
67. Burghardt AJ, Kazakia GJ, Sode M, de Papp AE, Link TM, Majumdar S: A longitudinal HR-pQCT study of alendronate treatment in postmenopausal women with low bone density: relations among density, cortical and trabecular microarchitecture, biomechanics, and bone turnover. J Bone Miner Res 2010, 25:2558-2571.

68. Tournis S, Samdanis V, Psarelis S, Liakou C, Antoniou J, Georgoulas T, Dontas I, Papaioannou N, Gazi S, Lyritis GP: Effect of rheumatoid arthritis on volumetric bone mineral density and bone geometry, assessed by peripheral quantitative computed tomography in postmenopausal women treated with bisphosphonates. J Rheumatol 2012, 39:1215-1220.

doi:10.1186/ar4180

Cite this article as: Aeberli D, Schett G: Cortical remodeling during menopause, rheumatoid arthritis, glucocorticoid and bisphosphonate therapy. Arthritis Research \& Therapy 2013, 15:208 